Conclusion: Rheumatoid arthritis patients are in increased risk of CV disease. PWV is considered as an independent risk factor of CVD. We proved increased arterial stiffness and vascular ageing in comparison to healthy controls. We did not find correlation between increased arterial stiffness and disease activity. All CVD risk factor intervention is necessary to improve the prognosis of patients. Further investigation is needed to establish the role of increased PWV in RA patients.

References:

[1] Reference Values for Arterial Stiffness' Collaboration. Determinants of pulse wave velocity in healthy people and in the presence of cardiovascular risk factors: 'establishing normal and reference values'. Eur Heart J. 2010;31(19):2338-2350.

[2] Pasquale Ambrosino, Marco Tasso, Roberta Lupoli, Alessandro Di Minno, Damiano Baldassarre, Elena Tremoli \& Matteo Nicola Dario Di Minno. Non-invasive assessment of arterial stiffness in patients with rheumatoid arthritis: A systematic review and meta-analysis of literature studies, Annals of Medicine, 2015; 47:6, 457-467.

Acknowledgments: IGA_LF_2019_006, MZ Č-RVO (FNOL-00098892, 87-21)

Disclosure of Interests: Markéta Schubertová: None declared, Andrea Smržová: None declared, Pavel Horak Speakers bureau: Pfizer, Abbvie, Eli lilly. Novartis, Roche, Sanofi, Martina Skácelová: None declared, Eva Lokočová: None declared, Zuzana Heřmanová: None declared, František Mrázek: None declared

DOI: 10.1136/annrheumdis-2020-eular.4802

\section{AB0265 REDUCTION OF APPENDICULAR SKELETAL MASS INDEX IS A PREDICTOR OF FRACTURE IN PATIENTS WITH RHEUMATOID ARTHRITIS BASED ON THE THREE-YEAR FOLLOW-UP DATA OF THE CHIKARA STUDY}

M. Tada ${ }^{1}$, Y. Yamada ${ }^{2}$, K. Mandai ${ }^{3}$, N. Hidaka ${ }^{1} .{ }^{1}$ Osaka City General Hospital, Orthopaedic Surgery, Osaka, Japan; ${ }^{2}$ Osaka City University Medical School, Orthopaedic Surgery, Osaka, Japan; ${ }^{3}$ Osaka Social Medical Center Hospital, Orthopaedic Surgery, Osaka, Japan

Background: Patients with rheumatoid arthritis (RA) have lower muscle mass ${ }^{1}$ and a higher risk of fragility fracture ${ }^{2}$ compared with healthy individuals. The predictors for fractures among baseline data and the chronological changes of disease activity, body composition, and muscle mass are unknown.

Objectives: The predictors for fractures were investigated over a 3-year period in a longitudinal study.

Methods: The 3-year follow-up data from a prospective observational study (CHIKARA study: Correlation researcH of sarcopenla, sKeletal muscle and disease Activity in Rheumatoid Arthritis) were used. The patients' fractures were counted, and correlations between fractures and disease activity, body composition, and sarcopenia were investigated. Muscle mass, body fat mass, total body water, bone mass, and basal metabolic rate were measured using a body composition analyzer. The fracture-free survival rate was calculated. The relationships between fractures and each parameter at baseline and the changes over the 3-year period $(\Delta)$ were investigated by univariate and multivariate analyses.

Results: A total of 100 patients (78 female, average age 68 years) were enrolled in this study; 12 patients (10 female and 2 male) had fractures during the 3-year follow-up, and the fracture-free survival rate was $86.9 \%$. The $\Delta$ modified Health Assessment Questionnaire (mHAQ), $\Delta$ weight, $\Delta$ muscle mass, $\Delta$ estimated bone mass, $\Delta$ basal metabolic rate, and $\Delta$ appendicular skeletal muscle index (ASMI) were predictors for fractures. On the other hand, body composition, disease activity, and sarcopenia at baseline were not correlated with fractures (Table 1). The $\Delta$ ASMI was an independent predictor for fractures on multivariate analysis (odds ratio:0.015, $\mathrm{P}=0.026$ ). The estimated cut-off value of the $\Delta$ ASMI was $0.14 \mathrm{~kg} / \mathrm{m}^{2}$ on receiver operating characteristic curve analysis (Figure). When the $\triangle \mathrm{ASMI}$ decrease was greater than or equal to $0.14 \mathrm{~kg} / \mathrm{m}^{2}$ for three years, the odds ratio of fractures was significantly increased 9.8 -fold, compared to a $\triangle \mathrm{ASMI}$ decrease less than $0.14 \mathrm{~kg} / \mathrm{m}^{2}(\mathrm{P}=0.001)$
Table 1. Predictors for fractures in patients with RA

\begin{tabular}{llc}
\hline & \multicolumn{2}{c}{ Univariate } \\
\hline & R value & P value \\
\hline Baseline & & \\
Age, year & 0.172 & 0.087 \\
DAS28-ESR & -0.083 & 0.411 \\
mHAQ & 0.077 & 0.447 \\
Weight, kg & 0.021 & 0.837 \\
Muscle mass, kg & -0.0035 & 0.728 \\
Estimated bone mass, kg & -0.020 & 0.845 \\
Sarcopenia & -0.093 & 0.356 \\
Change of 3-year period & & \\
$\Delta$ DAS28-ESR & 0.187 & 0.088 \\
$\Delta$ mHAQ & 0.224 & 0.040 \\
Weight, kg & -0.224 & 0.045 \\
Muscle mass, kg & -0.253 & 0.023 \\
$\Delta$ Estimated bone mass, $\mathrm{kg}$ & -0.236 & 0.034 \\
$\Delta$ Basal metabolic rate, $\mathrm{kcal} / \mathrm{day}$ & -0.248 & 0.025 \\
$\Delta$ Appendicular skeletal muscle index, $\mathrm{kg} / \mathrm{m}^{2}$ & -0.352 & 0.001 \\
\hline
\end{tabular}

Conclusion: The fracture-free survival rate was $86.9 \%$ in this 3-year longitudinal study. It was difficult to predict future fractures from the baseline data. Reduction of the ASMI was an independent predictor for fractures. Alleviating muscle mass loss may prevent fractures.

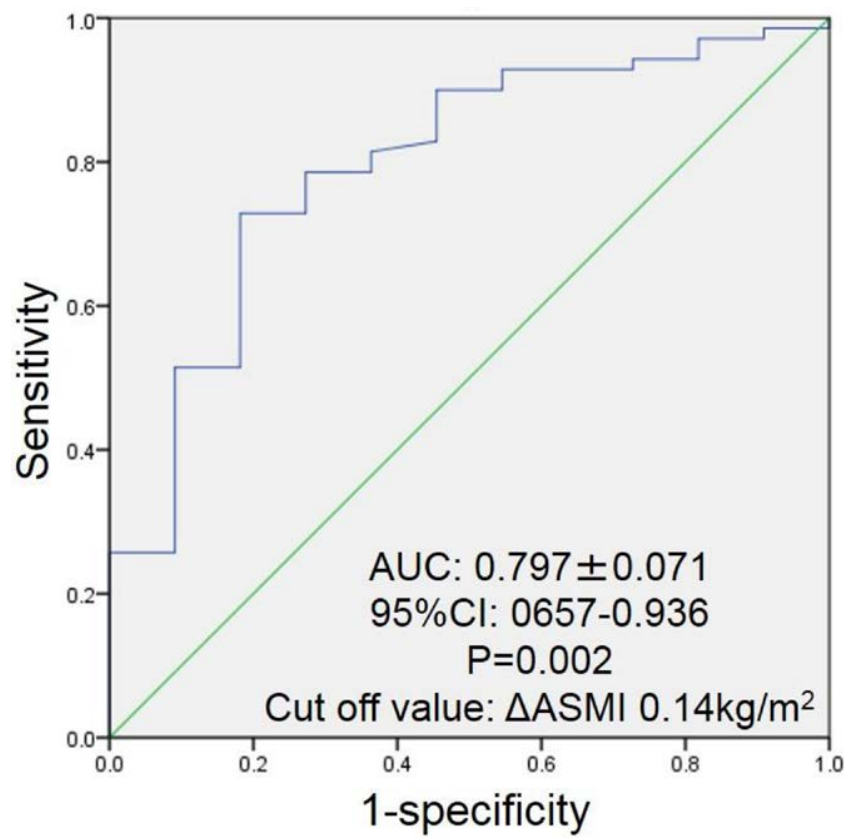

References:

[1] Inui K., Koike T., Tada M., et al. Sarcopenia is apparent in patients with rheumatoid arthritis, especially those with biologics -TOMORROW studyEULAR 2015 abstract (AB0359).

[2] van Staa TP, Geusens P, Bijlsma JW, et al. Clinical assessment of the longterm risk of fracture in patients with rheumatoid arthritis. Arthritis Rheum. 2006; 54: 3104-12.

Disclosure of Interests: None declared

DOI: 10.1136/annrheumdis-2020-eular.2064

\section{AB0266 \\ ANALYSIS OF STRESS AND FATIGUE IN PATIENTS WITH RHEUMATOID ARTHRITIS USING A DIGITIZING DEVICE}

M. Tada ${ }^{1}$, Y. Yamada ${ }^{2}$, K. Mandai ${ }^{3}$, N. Hidaka ${ }^{1} .{ }^{1}$ Osaka City General Hospital, Orthopaedic Surgery, Osaka, Japan; ${ }^{2}$ Osaka City University Medical School, Orthopaedic Surgery, Osaka, Japan; ${ }^{3}$ Osaka Social Medical Center Hospital, Orthopaedic Surgery, Osaka, Japan 